\title{
Libertad, autodeterminación e imputabilidad: El determinismo no necesitarista de Leibniz
}

\author{
Free will, self-determination and imputability: Leibniz's non- \\ necessitarist determinism \\ AGUSTÍN ECHAVARRÍA \\ Universidad de Navarra (España)
}

Recibido: 22-3-2012

Aprobado definitivamente: 17-10-2012

\begin{abstract}
RESUMEN
En el presente artículo se analiza la fundamentación leibniziana de la voluntad libre entendida como capacidad de autodeterminación, a partir de sus notas esenciales: espontaneidad, deliberación y contingencia. Al estar la voluntad determinada por la serie de percepciones que brotan de la naturaleza de la sustancia, el dominio de esta sobre sus propios actos es indirecto y diacrónico. Si bien Leibniz elude el necesitarismo mediante la atribución a la voluntad de la posibilidad lógica de obrar de forma que como obra, la imputabilidad moral de las acciones queda seriamente comprometida. El artículo concluye con una valoración crítica de la postura de Leibniz desde una perspectiva de la naturaleza de la voluntad como apertura trascendental al bien en cuanto tal.
\end{abstract}

\author{
PALABRAS CLAVE \\ LIBERTAD, AUTODETERMINACIÓN, IMPUTABILIDAD, DETERMINISMO, \\ LEIBNIZ
}

\begin{abstract}
In the present article we analyze Leibniz's foundation of free will, understood as a potency of self-determination, examining it from its essential features: spontaneity, deliberation and contingency. Since will is determined by the series of perceptions which flow from the nature of substance, its dominion over its own acts is indirect and diachronic. Even if Leibniz avoids necessitarianism by attributing the logical possibility of doing otherwise to the will, the actions' moral imputability is seriously compromised. The article concludes with a critical evaluation of Leibniz's position, from a perspective in which the nature of will is considered as a transcendental openness towards good as such.
\end{abstract}

\section{KEY WORDS}

FREE WILL, SELF-DETERMINATION, IMPUTABILITY, DETERMINISM, LEIBNIZ 


\section{INTRODUCCIÓN ${ }^{1}$}

EL INTENTO DE OFRECER UNA FUNDAMENTACIÓN DE LA LIBERTAD de las sustancias racionales es uno de los motivos centrales de la filosofía de Leibniz, quien pretende distanciarse en este punto de autores necesitaristas como Hobbes y Spinoza. ${ }^{2}$ La cuestión no reviste para Leibniz un interés meramente especulativo, sino también práctico. Solo la existencia de una auténtica voluntad libre puede garantizar la responsabilidad de los agentes sobre las propias acciones, solo las acciones libres resultan imputables desde el punto de vista moral.

En efecto, para que exista en ellas una libertad en un sentido relevante, es necesario que las sustancias racionales se determinen a sí mismas voluntariamente a poner o no sus actos, y a ponerlos de un modo o de otro, siguiendo o apartándose de lo que la inteligencia les presenta como bueno. Leibniz parece tener claro que el rasgo definitorio de la libertad consiste en la autodeterminación voluntaria: «Las criaturas inteligentes se determinan voluntariamente, las demás por cierta razón bruta». ${ }^{3}$ Ahora bien, la caracterización de la libertad como capacidad de autodeterminación recibe una interpretación completamente original dentro de su sistema. La finalidad del presente artículo es elucidar el significado y alcance que Leibniz atribuye a la libertad como capacidad de autodeterminación y, simultáneamente, realizar una valoración crítica de esta doctrina, a fin de establecer si es adecuada para garantizar la responsabilidad e imputabilidad moral de las acciones.

Se expondrán el primer lugar los lineamientos generales de su concepción de la libertad de la criatura racional: ${ }^{4}$ espontaneidad y deliberación. Se explicará en qué sentido Leibniz admite la «indiferencia» como una característica esencial de la libertad. Se mostrará de qué modo esa indiferencia (o «contingencia»), es el fundamento de la capacidad de autodeterminación, en tanto que hace posible el dominio de la voluntad sobre el juicio que la determina -si bien se trata de un dominio «diacrónico», dado el carácter no reflejo del acto voluntario-. Se explicará en que sentido esta concepción, si bien conduce a un «determinismo», evita hábilmente el «necesitarismo», al fundar la contingencia del acto libre en la mera no contradicción lógica. Se intentará mostrar que este «determinismo» no elimina, según Leibniz, la responsabilidad y la imputabilidad moral de las acciones, que solo requiere la consideración de la bondad o malicia efectiva de la voluntad. A modo de conclusión, se realizará una valoración crítica de la

\footnotetext{
${ }^{1}$ Se utilizarán las siguientes abreviaturas para citar las obras de Leibniz: A = Sämtliche Schriften und Briefe, herausgegeben von Preussischen Akademie der Wissenchaften, Deutschen Akademie der Wissenschaften zu Berlin, Darmstadt, 1923 y ss., Leipzig, 1938 y ss., Berlín, 1950 y ss., seguido del número de la serie (en romanos), del volumen y del número de página; GP = Die Philosophischen Schriften, herausgegeben von C. J. Gerhardt, Berlín, 1875-1890, reimp. Hildesheim, 1965, seguido del número del volumen (en romanos), y del número de página; Grua = Textes inédits d'apres les manuscrites de la bibliothèque provinciale de Hannover, publiés et annotés par G. Grua. Paris: Presses Universitaires de France, 1948, seguido del volumen y número de página; OFC $2=$ G. W. Leibniz. Obras filosóficas y científicas. 2. Metafísica, edición de A. L. González, Granada, 2010; DPG = Dissertation on Predestination and Grace, translated, edited and with an Introduction by Michael J. Murray. New Haven and London: Yale University Press, 2011, seguido del número de página y del número y letra del parágrafo y; EF = Escritos filosóficos, edición de E. de Olaso. Madrid: A. Machado, 2003.

${ }^{2}$ GP III, 572-573.

${ }^{3}$ DPG, 136-138, 557 (a). La traducción de los textos es mía, salvo que se indique lo contrario.

${ }^{4}$ Para un estudio exhaustivo de la cuestión, véase M.-T. Liske, Leibniz' Freiheitslehre. Die logischmetaphysischen Voraussetzungen von Leibniz’ Freiheitstheorie. Hamburg: Meiner, 1993; también C. Roldán Panadero, «Estudio preliminar. La salida leibniziana del laberinto de la libertad», en G. W. Leibniz, Escritos en torno a la libertad, el azar y el destino. Madrid: Tecnos, 1990, pp. IX-LXVII; y el más antiguo pero muy completo estudio de G. H. R. Parkinson, Leibniz on Human Freedom. Wiesbaden: Steiner, 1970.
} 
fundamentación leibniziana de la libertad, señalando como principal deficiencia la incapacidad de dar cuenta de la «indeterminación activa» de la voluntad, enraizada en la apertura trascendental propia de la naturaleza del entendimiento y la voluntad.

\section{NOTAS ESENCIALES DE LA LIBERTAD: ESPONTANEIDAD Y DELIBERACIÓN}

Las notas fundamentales que caracterizan a la libertad según Leibniz son la «espontaneidad» y la «deliberación». En la Confessio philosophi, Leibniz sostiene que, supuesta la definición de Aristóteles, según la cual se dice que algo es espontáneo «[...] cuando el principio del actuar está en el agente», ${ }^{5}$ se llamará «libre» a aquello que es «espontáneo con elección». ${ }^{6}$ En su conversación con Stensen Leibniz manifiesta su adhesión a la «antigua» definición de libertad, según la cual la libertad es una especie dentro del género de lo espontáneo, a saber, la «espontaneidad racional». ${ }^{7}$ En los Nouveaux Essais, atribuye explícitamente esta definición al Estagirita: «[...] Aristóteles ha remarcado ya de modo acertado que para llamar libres a las acciones, exigimos no sólo que sean espontáneas, sino también que sean deliberadas». ${ }^{8}$ En los Essais de Théodicée, añade que en la espontaneidad y la elección reside precisamente el «imperio» de la criatura racional sobre sus propias acciones. ${ }^{9}$

¿En qué consiste la primera de estas notas de la libertad, a saber, la «espontaneidad»? Según Leibniz se trata de una característica común a todas las sustancias, a saber, el que estas sean el principio de sus propias acciones. ${ }^{10}$ Lo que especifica a las acciones libres como tales es la otra nota esencial, la «deliberación»o «elección», es decir, el hecho de que estas acciones broten de la sustancia en virtud de un previo conocimiento racional, y de una consecuente adhesión tendencial al bien conocido. ${ }^{11}$ Por eso Leibniz no duda en identificar la libertad con el «apetito racional», es decir, con la misma voluntad: «Libertad y voluntad significan lo mismo. Pues libre es lo mismo que espontáneo con razón, y querer es ser llevado a actuar por una razón percibida mediante el entendimiento; $[\ldots] \gg .^{12}$

La libertad estriba en el carácter racional o intelectual de la acción de la voluntad, previamente configurada por la captación del bien contenido en ella: «[...] la más alta libertad consiste en ser impelido a lo mejor por la recta razón». ${ }^{13}$ Tanto más libre será una inteligencia cuanto más se determine a sí misma por las razones del bien. ${ }^{14}$ Esta concepción de la libertad sitúa a Leibniz en una posición fuertemente intelectualista: si algo es suficientemente captado como bueno por la inteligencia,

\footnotetext{
${ }^{5}$ A VI, 3, 133 (trad. OFC 2, 46).

${ }^{6}$ Ibid. (trad. OFC 2, 46). La doctrina acerca de la libertad de la criatura racional fue desarrollada tempranamente por Leibniz, sin sufrir prácticamente alteraciones a lo largo de su vida. Véase J. D. Davidson, «Leibniz on the Labyrinth of Freedom: Two Early Texts», The Leibniz Review XIII (2003), pp. $19-43$.

${ }^{7}$ A VI, 3, 133.

${ }^{8}$ A VI, 6, 175-176; DPG, 130, § 43 (a).

${ }^{9}$ GP VI, $122, \S 34$.

${ }^{10}$ GP VI, 138, § 65. Acerca de los distintos matices que la noción de «espontaneidad» adquiere en la obra de Leibniz, y cómo se integran en su pensamiento, véase D. Rutherford, «Leibniz on Spontaneity», en D. Rutherford, J. Cover (eds.), Leibniz. Nature and Freedom. New York: Oxford University Press, 2005, pp. 156-180.

${ }^{11}$ DPG $, 130, \S 42$ (h).

${ }^{12}$ GP IV, 362-363 (trad. EF, 491).

${ }^{13}$ A II 1, 186-187.

${ }^{14}$ A VI, 4B, 1409; DPG, 110, § 34 (c).
} 
determinará de modo infalible el querer de la voluntad, ${ }^{15}$ lo cual se da máximamente en el caso de la libertad suprema de Dios, que no puede errar en la elección de lo mejor. ${ }^{16}$

Por eso Leibniz sitúa la esencia y la raíz metafísica de la libertad de la criatura racional en aquello que es imagen de la libertad divina -a saber, el moverse a actuar en virtud de la consideración del bien en cuanto tal-, y no en aquello que es solo propio de la libertad en tanto que «creada»-esto es, el poder decaer del bien ${ }^{17}-$.

Si bien la captación de algo como mejor inclina y hasta determina infaliblemente a la voluntad, no obstante esta inclinación no impone a la voluntad una necesidad absoluta. ${ }^{18}$ Esta «ausencia de necesidad» es también una nota que pertenece a la esencia de la libertad. ${ }^{19}$ Así, Leibniz explica en sus Nouveaux Essais que el fundamento de lo que habitualmente se conoce con el nombre de «libre arbitrio», reside en el hecho de que «[...] las más fuertes razones o impresiones que el entendimiento presenta a la voluntad no impiden que el acto de la voluntad sea contingente, y nunca le confieren una necesidad absoluta o, por así decirlo, metafísica. Y es en este sentido en el que yo acostumbro a decir que el entendimiento puede determinar a la voluntad, según la prevalencia de las percepciones y razones de una manera tal que, al mismo tiempo que es segura e infalible, inclina sin hacer necesario». ${ }^{20}$

\section{INDIFERENCIA Y CONTINGENCIA}

La ausencia de necesidad inherente a la libertad no debe ser considerada como un añadido extrínseco a la «espontaneidad racional»; antes bien, dado que la necesidad absoluta es «ciega», y excluye por completo la deliberación, esta última es inseparable de la contingencia. ${ }^{21} \mathrm{Si}$ las condiciones ya enumeradas por Aristóteles -espontaneidad y deliberación- son bien entendidas, no hace falta agregar ningún otro elemento para caracterizar la libertad. ${ }^{22}$ No obstante, «[...] los escolásticos reclaman todavía una tercera, a la cual llaman indiferencia. Y, en efecto, es preciso admitirla, si la indiferencia significa lo mismo que contingencia; pues ya he dicho anteriormente que la libertad debe excluir una necesidad absoluta y metafísica o lógica». ${ }^{23}$

Leibniz concede que la «indiferencia» es una característica esencial de la libertad, pero aquella indiferencia que se identifica con la contingencia o con la falta de necesidad. ${ }^{24}$ No tiene nada que ver con la así llamada «indiferencia de equilibrio» característica del molinismo, es decir, aquella tesis según la cual la voluntad libre es una facultad carente de toda inclinación que la determine más hacia un lado que hacia otro. ${ }^{25}$ Leibniz buscó expresamente distanciarse a lo largo de su vida de esta posición, por

\footnotetext{
${ }^{15} \mathrm{DPG}, 110, \S 34$ (c).

${ }^{16}$ A VI, 3, 135.

17 A VI, 4B, 2577.

${ }^{18}$ GP VI, 300, § 310. Acerca de este punto, véase J. M. Torralba, «La libertad posible. Acerca de la noción leibniciana de «inclinar sin necesidad»», Anuario Filosófico XXXVIII/1 (2005), 279-290.

${ }^{19}$ A VI, 4B, 1455; Grua II, 482; DPG, 130, § 43 (a).

${ }^{20} \mathrm{~A}$ VI, 6, 175.

${ }^{21} \mathrm{GP} \mathrm{VI}, 441, \S 20$.

${ }^{22}$ GP VI, 296, § 302.

${ }^{23}$ Ibid.

${ }^{24}$ A VI, 4B, 1454-1455.

${ }^{25}$ A VI, 4B, 1455; GP VI, 128, § 46.
} 
considerarla «absurda e inaudita», ${ }^{26}$ una quimera que no se da nunca en la naturaleza, ${ }^{27}$ y que es imposible de suyo. ${ }^{28}$

Si Leibniz rechaza la indiferencia de equilibrio o «indiferencia absoluta», es porque considera que, previamente al acto de elección, la voluntad posee siempre una inclinación determinada hacia alguna de las alternativas, y que no es posible dar una explicación de este paso de la voluntad a la acción «[...] sin reconocer que hay una determinación en el estado precedente de la criatura libre, que la inclina a determinarse». ${ }^{29} \mathrm{Si}$ la voluntad ejerce su acto, y lo ejerce en un sentido o en otro es porque siempre se encuentra más inclinada a obrar que a no obrar, y a obrar en un sentido más que en otro, aun cuando el sujeto que ejerce la acción no se aperciba perfecta e inmediatamente de las razones que han determinado a su voluntad en esa elección. $^{30}$

No obstante, la voluntad conserva siempre una «indiferencia respectiva o limitada», es decir, aunque la voluntad esté más inclinada a un lado que a otro, puede actuar o no actuar, aun cuando sea «cierto» que actuará. ${ }^{31}$ Nunca es tanta la inclinación en la mente que se siga necesariamente el acto: «Hace falta saber que es verdad siempre que nuestra libertad y la de todas las otras sustancias inteligentes incluido Dios mismo, viene acompañada de un cierto grado de indiferencia o contingencia, que ha sido definida de tal forma que nosotros y esas sustancias jamás somos necesitados, porque lo contrario de aquello que hacemos sigue siendo siempre posible, o no implica contradicción». ${ }^{32}$

Leibniz sitúa la contingencia propia de la libertad en la «posibilidad de hacer lo contrario» de aquello hacia lo que la voluntad está más inclinada. ${ }^{33}$ Esto significa que en la progresión de nuestros pensamientos e inclinaciones nunca nos encontramos en un estado tal que, consideradas todas las circunstancias internas y externas, sea absolutamente imposible obrar lo contrario al instante siguiente, aunque sea «cierto e infalible», al menos para Dios, lo que haremos. ${ }^{34} \mathrm{Si}$ la criatura racional es capaz de ejercer o no su acto, y de ejercerlo en un sentido o en otro, se debe a que, en el proceso de la deliberación que precede al acto de elección libre, el alma considera la conexión entre determinados fines y los medios conducentes hacia esos fines de tal forma que el juicio mediante el cual establece tal conexión, y que la determina a actuar, no es necesario sino contingente, es inclinante, no necesitante. ${ }^{35}$ Ahora bien, ¿cómo se da la relación entre esa contingencia y la capacidad de la voluntad de determinarse a sí misma?

\section{DOMINIO DIACRÓNICO DEL JUICIO}

\footnotetext{
${ }^{26}$ A VI, 3, 133. Para un estudio sobre la crítica leibniziana a la indiferencia de equilibrio, véase S. Greenberg, «Leibniz Against Molinism: Freedom, Indifference, and the Nature of the Will», en D. Rutherford, J. Cover (eds.), Leibniz. Nature and Freedom, pp. 217-233.

${ }^{27}$ A VI, 4B, 1455; DPG, 130, § 42 (h).

${ }^{28}$ GP VI, 306, § 320; A VI, 4B, 1408. En el mismo sentido, Leibniz declara inexistente el célebre caso del «asno de Buridán», muerto de hambre por no poder elegir entre dos partidos exactamente iguales: GP VI, $129, \S 49$.

${ }^{29}$ GP VI, 129, § 48.

${ }^{30}$ GP VI, 123, § 35.

${ }^{31}$ A VI, 4B, 1455.

${ }^{32}$ Grua II, 480-481.

${ }^{33}$ DPG, 110, $\$ 35$ (b).

${ }^{34}$ DPG, 130, § 43 (a)

${ }^{35}$ DPG, 70, § 14 (d).
} 
Para responder a esta cuestión hay que considerar que no cabe ninguna duda de que, al menos en su intención expresa, Leibniz considera que la libertad es una «potencia activa real», que hace a la criatura racional capaz de autodeterminación, en la medida en que es dueña de su propio juicio; en esto, él se considera a sí mismo deudor de la doctrina de Tomás de Aquino. ${ }^{36}$ La sustancia libre no sólo tiene la capacidad para elegir una u otra alternativa -libertad de «especificación»-, sino que tiene además la capacidad de suspender el juicio de elección -libertad de «ejercicio»-: «[...] hablando de una forma absoluta, la voluntad es indiferente en tanto que se la opone a la necesidad, y posee el poder de actuar de otra manera o incluso de suspender completamente su acción; ambas partes de la alternativa son y siguen siendo posibles». ${ }^{37}$

El dominio que la criatura racional tiene sobre el propio juicio descansa en la insuficiencia motivadora de la apariencia de bien que presentan las diferentes opciones ofrecidas a la inteligencia, que nunca es tanta ni tan evidente que impida dejar de pensar en ellas, o mudar el objeto de la consideración, suspendiendo así la última decisión. ${ }^{38}$ Leibniz llega afirmar que la indiferencia que acompaña a la libertad creada implica no sólo la ausencia de «necesidad metafísica», sino también de «necesidad física»: ${ }^{39}$ «[...] no es de necesidad física que los hombres en esta vida elijan algún bien particular, por atractivo y vistoso que sea; [...]». ${ }^{40}$ Así, aunque una substancia libre nunca elige lo que le aparece como peor, «[...] sin embargo no siempre elige lo que en el momento presente aparece como mejor; porque puede aplazar y suspender el juicio hasta una posterior deliberación, y desviar la mente para que piense en otras cosas»». ${ }^{41}$

¿Contradice esta afirmación de que no siempre elegimos lo que actualmente consideramos mejor aquella otra tesis leibniziana según la cual el bien real o aparente, captado como tal por la inteligencia, determina de modo infalible el querer de la voluntad? Esta aparente contradicción se esfuma si tenemos que cuando Leibniz dice que podemos suspender la elección de aquello que consideramos bueno, no habla en sentido "sincrónico», sino «diacrónico». ${ }^{42}$ Puede darse el caso de que juzguemos algo como bueno en el tiempo de la deliberación anterior al instante de la elección, pero que, en el lapso que transcurre entre ese juicio y el acto de elección, la serie de nuestros pensamientos se vea interrumpida o desviada hacia otros objetos: «[...] cualquiera sea la percepción que uno tenga del bien, el esfuerzo de obrar según el juicio, que a mi entender constituye la esencia de la voluntad, es algo distinto: así, como hace falta tiempo para llevar ese esfuerzo a su culmen, puede ser suspendido, e igualmente puede ser cambiado por una nueva percepción o inclinación que se le atraviese, que desvíe al espíritu, y que le haga formar en algún caso el juicio contrario. Esto es lo que hace que nuestra alma tenga tantos medios para resistir a la verdad que ella conoce, y que haya un

\footnotetext{
${ }^{36}$ A VI, 4B, 1451. Acerca de las Fuentes escolásticas de la doctrina leibniziana sobre el dominio del propio juicio en el acto libre, véase el estupendo artículo de M. J. Murray, «Intellect, Will, and Freedom», The Leibniz Review VI (1996), pp. 25-59.

${ }^{37}$ A VI, 4B, 1575 (trad. OFC 2, 194)

${ }^{38}$ A VI, 4B, 1455.

39 A VI, 4B, 1520. En virtud de esta afirmación, M. Murray ha sostenido que Leibniz profesa un «compatibilismo mitigado», que distingue entre la «necesidad moral»-de la que estaría afectada toda decisión libre-, de la «necesidad física»-de la cual las acciones libres estarían exentas-: M. J. Murray, «Spontaneity and Freedom in Leibniz», en D. Rutherford, J. Cover (eds.), Leibniz. Nature and Freedom, pp. 194-216.

${ }^{40}$ A VI, 4B, 1520 (trad. OFC 2, 157).

${ }^{41}$ Ibid. (trad. OFC 2, 156).

${ }^{42}$ Vease al respecto F. Piro, Spontaneitá e ragion sufficiente, Determinismo e filosofía dell'azione in Leibniz. Roma: Edizioni de Storia e Letteratura, 2002 p. 190.
} 
trayecto tan grande desde el espíritu al corazón: [...]. Así, la ligazón entre el juicio y la voluntad no es tan necesaria como uno podría pensar»». ${ }^{43}$

Pareciera que la capacidad de suspender la elección no reside entonces en un «dominio» de la voluntad sobre el juicio que determina la elección, sino que se resuelve en la mera posibilidad de que una cierta sucesión de pensamientos o percepciones que tienen lugar en nuestra alma -y que conduciría de suyo a un acto de elección determinado- se vea interrumpida por otra serie de pensamientos o percepciones que ganan su lugar, prevaleciendo sobre la anterior, y conduciéndola a una elección contraria. ${ }^{44}$ Consideradas las cosas desde un punto de vista «sincrónico», Leibniz sostiene que en el instante mismo en el que la voluntad elige un objeto, siempre está determinada a querer lo que se considera mejor en ese instante, de forma tal que, aunque elegimos lo que queremos, el querer mismo no depende de nuestra elección, sino de nuestras inclinaciones y de los objetos que se nos presentan. ${ }^{45}$

A diferencia de lo que sucede en el caso de Dios, que está «moralmente» determinado a elegir lo que realmente es mejor, en el resto de las sustancias racionales «[...] las pasiones a menudo toman el lugar de la razón, y por eso puede decirse con respecto a la voluntad en general: que la elección sigue la inclinación más grande, bajo la cual comprendo tanto las pasiones como las razones verdaderas o aparentes». ${ }^{46} \mathrm{La}$ voluntad humana se encuentra entonces, según Leibniz, completamente «determinada» por el conflicto de sus representaciones e inclinaciones y su acto de elección siempre obedece a causas determinantes, provenientes tanto de la razón como de las pasiones ${ }^{47}$, aunque no siempre nos apercibamos de ellas. ${ }^{48}$ Existen siempre en el espíritu creado numerosas influencias imperceptibles, pequeños movimientos de los cuales no nos apercibimos y que, no obstante, nos inclinan a obrar de un modo determinado. ${ }^{49}$

En el orden de las percepciones que determinan los movimientos del alma creada, algunas son distintas $-\mathrm{y}$ por tanto nos apercibimos de ellas- y otras son confusas -y no nos apercibimos de ellas-, mientras que sólo Dios tiene el privilegio de la total claridad y distinción de las razones de su acción. ${ }^{50}$ El alma creada, por el contrario, jamás es totalmente transparente ante sí misma, nunca tiene ante sí la serie total de sus percepciones y de las motivaciones que impulsan sus propias acciones: «[...] si nosotros no siempre advertimos la razón que nos determina, o más bien, por la cual nosotros nos determinamos, es porque somos también poco capaces de apercibirnos de todo el juego de nuestro espíritu y de sus pensamientos, la mayor parte de las veces imperceptibles y confusos, como lo somos para desentrañar todos los mecanismos que la naturaleza hace jugar en los cuerpos». ${ }^{51}$ Así, aunque nosotros nos creamos totalmente dueños de nuestro presente acto de querer, esta apariencia se debe a nuestra ignorancia de las causas que lo determinan..$^{52}$

\footnotetext{
${ }^{43}$ GP VI, 301, § 311.

${ }^{44}$ A VI, 6, 181.

45 Grua II, 482.

${ }^{46}$ GP III, 401-402.

47 GP VI, 130, § 51.

${ }^{48}$ Grua II, 482.

${ }^{49}$ GP VI, 128, § 46. Acerca de la temprana formación de esta teoría determinista de la acción, véase M. Schneider, «Leibniz' Theorie der Aktion im Jahrzehnt vor dem Discours de métaphysique 1677-1686», Studia Leibnitiana XXXIII (2001), pp. 98-121.

${ }^{50}$ GP VI, 137, § 64.

${ }^{51}$ A VI, 6, 178

${ }^{52}$ Grua II, 480.
} 


\section{EL CARÁCTER NO REFLEJO DE LA VOLUNTAD LIBRE}

De lo dicho se desprende que la voluntad creada no es «reflexiva», es decir, no puede operar sobre su propio acto. Leibniz sostiene, en efecto, que la voluntad creada sólo puede querer los objetos que se le presentan como buenos, pero no puede querer su propio acto de querer: «[...] aunque esté en nuestro poder hacer lo que queremos, sin embargo no está en nuestro poder querer lo que queremos, sino lo que percibimos como agradable o lo que estimamos bueno»». ${ }^{53}$ Dicho en otros términos, es imposible, según Leibniz, que el acto de nuestra voluntad recaiga sobre la volición misma, es decir, que la voluntad sea causa de sí misma en el acto de querer: «Por lo que respecta a la volición misma, es algo impropio decir que ella es objeto de la voluntad libre. Nosotros queremos actuar, hablando propiamente, y no queremos querer; de otro modo, todavía podríamos decir que queremos tener la voluntad de querer, y así iríamos al infinito». ${ }^{54}$

La razón de este rechazo a la reflexividad de la voluntad responde al hecho de que Leibniz considera que una libertad que tuviese un dominio actual sobre su propio acto de querer sería una libertad «absoluta», desligada de toda razón, que coincidiría con la quimera molinista de una voluntad absolutamente indiferente. ${ }^{55}$ Por el contrario, Leibniz considera que nuestra voluntad es una voluntad «causada» por algo distinto de ella misma -como ya se ha visto, por la naturaleza de los objetos y por las inclinaciones del espíritu que conforman su naturaleza individual-, que no puede imperar su propio acto de querer presente. ${ }^{56}$ Así, del mismo modo que nuestra opinión no está sujeta al poder de nuestra voluntad, tampoco nuestra voluntad está sujeta al poder de nuestra voluntad. ${ }^{57}$

Esto no implica que la voluntad de la criatura no tenga ningún poder sobre sus propios actos; aunque no pueda imperarlos directamente en el presente, puede influir de modo indirecto en los actos futuros, tomando medidas para llegar a querer, en otro momento, lo que actualmente no quiere: «[...] sin embargo no hace falta disimular que por medio de las acciones voluntarias contribuimos a menudo indirectamente a otras acciones voluntarias, y aunque uno no pueda querer lo que quiere, como igualmente uno no puede juzgar lo que quiere, uno puede sin embargo actuar en cierto modo por anticipación, de modo que uno juzgue o quiera con el tiempo lo que uno desearía poder querer o juzgar hoy». ${ }^{58}$

El alma tiene un poder indirecto sobre sus percepciones, sean éstas confusas o distintas, porque puede entrar, si le parece bueno, en determinadas progresiones de pensamientos; ${ }^{59}$ de esta manera tiene también un control indirecto sobre las pasiones y voliciones futuras. ${ }^{60}$ No tenemos el poder de querer lo que actualmente queremos, pero nuestro acto actual de querer contribuye a que la serie de nuestras percepciones y apeticiones futuras tome un curso determinado $u$ otro. ${ }^{61}$

Este dominio indirecto y diacrónico de la voluntad sobre sus actos futuros no desmiente el hecho de que, tomados en el instante en que se producen, cada uno de sus actos la voluntad es causado por las inclinaciones anteriores, de suerte que «[...] la

\footnotetext{
${ }^{53}$ A VI, 3, 132 (trad. OFC 2, 45).

${ }^{54}$ GP VI, 130, § 51; A VI, 6, 182.

${ }^{55}$ A VI, 4B, 1408.

${ }^{56}$ Grua II, 482.

${ }^{57}$ A VI, 3, 132.

${ }^{58}$ A VI, 6, 182; GP VI, 138, § 64.

${ }^{59}$ Ibid.

${ }^{60}$ GP VI, 137-138, § 64.

${ }^{61}$ GP VI, 296, § 301; GP VI, 357, § 404.
} 
elección es siempre determinada por la percepción». ${ }^{62}$ Esto puede afirmarse también respecto de las voliciones actuales que influirán en voliciones futuras, por lo que, aunque se sitúen ciertas voliciones como causa indirecta de otras voliciones, siempre seguirá siendo cierto que la causa última de la serie total de los actos voluntarios estará fuera de la voluntad misma, lo cual parece poner en entredicho la capacidad real de «autodeterminación» de las sustancias.

\section{LIBERTAD Y «EXPRESIÓN»: LA SUPERACIÓN DE LA DIALÉCTICA «AUTONOMÍA- HETERONOMÍA»}

En efecto, si la voluntad sigue siempre a la inclinación más fuerte, y la inclinación depende de la serie de objetos de percepción y apetición que se le presentan a la sustancia, y, más aun, si los objetos se presentan según una concatenación que depende en última instancia del orden de la serie total de cosas o «mundo» al que cada sustancia pertenece, parece entonces que la determinación de los actos de la voluntad no proviene de ella misma, sino de ese orden, y es entonces heterónoma a la sustancia misma: «[...] la razón última del querer está fuera del que quiere. Y ha sido demostrado que al final todo esto se refunde en la serie de las cosas, es decir, en la armonía universal». ${ }^{63}$ ¿En qué sentido puede entonces hablarse de «autodeterminación» de la sustancia libre?

La respuesta a esta pregunta requiere referirse al núcleo especulativo en el que confluyen en el pensamiento de Leibniz la metafísica con la teoría de la acción. Me refiero a la tesis de la naturaleza «expresiva» de la sustancia individual, en virtud de la cual nada hay propiamente «externo» a las sustancias, porque cada una de ellas expresa y contiene en sí - a través de sus percepciones y apeticiones- la totalidad del universo al que está intrínsecamente conectada, en virtud de sus relaciones de composibilidad. ${ }^{64}$ Es cierto, por una parte, que las sustancias libres no son determinadas por ninguna impresión que sea propiamente externa a ellas mismas, sino que sólo son determinadas por la concatenación interna de sus percepciones y apeticiones. ${ }^{65}$ Ahora bien, estas percepciones y apeticiones no son más que el reflejo o la impresión del universo en nosotros, ${ }^{66}$ de manera que, tanto cuando actuamos como cuando padecemos, estamos determinados a actuar y padecer de acuerdo con aquello que fluye de nuestra naturaleza individual, «acomodada» según el orden de la armonía del universo. ${ }^{67}$

Mediante esta recíproca co-determinación y acomodación ontológica entre la naturaleza de la sustancia individual y la serie de cosas a la que ésta pertenece, Leibniz puede superar la antinomia entre heteronomía y autonomía, entre un determinismo puramente externalista y una total autodeterminación en la causalidad del acto libre, internalizando en la propia sustancia intelectual el principio inmanente de sus

\footnotetext{
${ }^{62}$ A VI, 6, 182.

${ }^{63}$ A VI, 3, 136 (trad. OFC 2, 49).

${ }^{64}$ A VI, 4B, 1542; A VI, 4B, 1553-1554; A VI, 4B, 1618 ; A II, 2, 231; GP III, 69 ; GP II, 311. Sobre la idea leibniziana de expresión, véase M. Kulstad, «Leibniz's concept of expression», Studia Leibnitiana XI/1 (1977), pp. 55-76 y «Leibniz on Expression: Reflections After Three Decades», en H. Breger, J. Herbst, S. Erdner, VIII. Internationaler Leibniz-Kongress. Einheit in der Vielheit. Hannover: Hartmann, 2006, pp. 413-419; Ghio, M., Il concetto di expresione in Leibniz en ella tradizione platónico-cristiana. Torino: Studi e Ricerche di Storia della Filosofia, 1979; C. Swoyer, «Leibnizian Expression», Journal of ther History of Philosophy XXXIII/1 (1995), pp. 65-99.

${ }^{65}$ DPG, 62-64, § 11 (e).

${ }^{66}$ Grua II, 480.

${ }^{67}$ Grua II, 481.
} 
operaciones, que incluye una intrínseca correlación con el mundo: «Cuando los antiguos han hablado de aquello que es $\dot{\varepsilon} \varphi \grave{\eta} \mu \mathrm{\imath} v$, o cuando nosotros hablamos de aquello que depende de nosotros, de la espontaneidad, del principio interno de nuestras acciones, no excluimos la representación de las cosas externas, porque estas representaciones se encuentran en nuestras almas; ellas forman parte de las modificaciones del principio activo que está en nosotros». ${ }^{68}$

Sigue siendo válida la afirmación de que estamos siempre perfectamente «predeterminados»-en la medida en que el conjunto de nuestras disposiciones e impresiones conforman una «inclinación total prevalente», que mueve nuestra voluntad de modo infalible-, aunque el principio próximo de la acción esté en nosotros mismos. ${ }^{69}$ Sigue siendo la sustancia racional la que se determina a sí misma en virtud de su propio principio activo, tomando como base las razones e inclinaciones presentes en ella: «La verdad es que el alma, o la sustancia que piensa, entiende las razones, y siente las inclinaciones, y se determina según la prevalencia de las representaciones que modifican su fuerza activa, para especificar la acción». ${ }^{70}$

No obstante, queda también claro que la capacidad de autodeterminación en la que la libertad estriba, no reside según Leibniz en un genuino imperio de la voluntad sobre el juicio que especifica su acción, sino que reside toda ella en la espontaneidad, ${ }^{71}$ es decir, en el que la sustancia misma sea el principio de sus acciones: «Se ve también que toda sustancia tiene una perfecta espontaneidad (que deviene libertad en las sustancias dotadas de inteligencia), que todo lo que le acontece es algo que sigue a su idea o a su ser, y que no la determina nada, salvo sólo Dios». ${ }^{72}$ La autodeterminación de la libertad significa para Leibniz que todas las acciones de la voluntad provienen de la misma sustancia, ${ }^{73}$ es decir, de su naturaleza individual constituida por una determinada configuración de percepciones y apeticiones-, no que las acciones voluntarias sean «imperadas» por la propia voluntad.

\section{VII. «DETERMINISMO» NO «NECESITARISTA» O LA MODALIZACIÓN DE LA LIBERTAD}

Según se ha dicho, Leibniz no pretende en ningún momento eludir la inexorable conclusión de que todos los actos libres de las criaturas están en realidad perfectamente determinados, aunque no por ello se cree obligado a caer en el necesitarismo: «Todo es entonces cierto y determinado por adelantado en el hombre, como en todo lo demás, y el alma humana es una especie de autómata espiritual, aunque las acciones contingentes en general, y las acciones libres en particular, no sean necesarias por eso con una necesidad absoluta, la cual sería verdaderamente incompatible con la contingencia» ${ }^{74}$

Leibniz sostiene que es muy grande la diferencia que media entre la «determinación»y la «necesidad»: si bien la conexión de nuestros pensamientos y movimientos está completamente determinada, ${ }^{75}$ eso no implica en absoluto que esa conexión sea absolutamente necesaria: «Así, si por la necesidad se entiende la determinación cierta que un conocimiento perfecto de todas las circunstancias podría hacer prever a un espíritu perfecto de lo que sucede dentro y fuera del hombre;

\footnotetext{
${ }^{68}$ GP VI, 416.

${ }^{69}$ Grua II, 480.

${ }^{70}$ GP VI, 416.

${ }^{71}$ GP VI, 296, § 301.

${ }^{72}$ A VI, 4B, 1581 (trad. OFC 2, 198).

${ }^{73}$ A VI, 4B, 1451.

74 GP VI, 132, § 54.

${ }^{75}$ A VI, 6, 178.
} 
entonces, dado que es seguro que los pensamientos están tan determinados como los movimientos que representan, todo acto libre sería necesario: pero hace falta distinguir lo necesario de lo que es contingente aunque determinado». ${ }^{76}$

En tal sentido, no debe tenerse ningún reparo en afirmar que la doctrina de Leibniz es decididamente «determinista» ${ }^{77}$-porque la voluntad se determina siempre ciertamente por las inclinaciones que se siguen de los motivos más fuertes- ${ }^{78}$ aunque no por ello pueda tildársela de «necesitarista». La pregunta que cabe hacerse es si en esta concepción determinista de la acción hay lugar para comprender la libertad como una potencia real, capaz de autodeterminarse poner o no su propio acto, y a ponerlo de un modo o de otro.

Según se ha visto, Leibniz hace depender tal potencia real del dominio que la criatura tiene sobre su propia acción, por ser esta contingente. Ahora bien, cada vez que se encuentra forzado a definir con precisión la contingencia que acompaña a la voluntad, Leibniz lo hace en términos puramente lógicos. La contingencia reside en la mera pensabilidad o no contradictoriedad de la acción contraria a la ejercida: «Cada vez que se propone una elección, por ejemplo la de salir o no salir, surge la cuestión de si con todas las circunstancias internas o externas, los motivos, las percepciones, las disposiciones, las impresiones, las pasiones e inclinaciones tomadas conjuntamente, estoy todavía en un estado de contingencia, o si estoy necesitado de tomar por ejemplo la elección de salir. Es decir, si esta proposición verdadera y determinada en efecto, en todas esas circunstancias, tomadas en conjunto, elegiré salir, es contingente o necesaria. A esto yo respondo que ella es contingente, porque ni yo ni ningún otro espíritu más esclarecido que yo podría demostrar que lo opuesto a esta verdad implica contradicción». ${ }^{79}$

La proposición que enuncia la realización del acto contrario al que efectivamente la libertad realiza, no es contradictoria, esto es, es una proposición que enuncia una verdad perteneciente a otro mundo posible, diferente del actual. La «potencia real» del sujeto se ve reducida así a la «modalidad alética». En tal sentido, es preciso dar la razón a Antonio Millán-Puelles, quien haciendo un balance de la doctrina leibniziana de la libertad, afirma con respecto a la acción libre: «Esta acción es, en efecto, contingente por no ser metafísicamente imposible que no ocurra; pero si la voluntad, al elegir, se encuentra determinada por algo que ella no es, entonces la voluntad no es dueña de su elección y carece, por tanto, de libertad de arbitrio». ${ }^{80}$

\section{LIBERTAD E IMPUTABILIDAD}

Las consecuencias metafísicas de esta reducción modal de la libertad creada con respecto a la responsabilidad moral de sus acciones son problemáticas. Surge en primer lugar, surge la pregunta de si las criaturas tienen o no la «posibilidad real» y no meramente lógica de obrar de otro modo, o si están ontológicamente determinadas a realizar sus acciones, sean estas buenas o malas. Leibniz se plantea la cuestión con respecto al pecado de Adán ¿Era Adán realmente capaz de obrar bien o mal? La respuesta es clara: «El sería capaz absolutamente, pero en este mundo posible que Dios

\footnotetext{
76 Ibid.

77 Acerca de la peculiar forma que adopta el determinismo de Leibniz, véase R. M. Adams, Leibniz: Determinist, Theist, Idealist. New York/Oxford, Oxford University Press, 1994.

${ }^{78}$ GP VI, 296, § 302.

${ }^{79}$ GP III, 401.

${ }^{80}$ A. Millán-Puelles, El valor de la libertad. Madrid: Rialp, 1995, p. 118.
} 
ha elegido, está contenido que él se determine al mal libremente». ${ }^{81}$ La capacidad de evitar el mal no reside, como potencia real, en el sujeto que ha sido puesto en la existencia, sino que se refiere a una acción posible perteneciente a la «contraparte» de tal individuo en otro mundo posible.

La cuestión reviste mayor gravedad si consideramos que los individuos no conservan una identidad ontológica a través de los mundos posibles; cambiando una mínima determinación en la misma noción de cada uno de ellos, se obtiene un individuo totalmente diferente, mutando a su vez la serie completa de cosas. ${ }^{82}$ De esto se desprende no sólo que determinados individuos están determinados a realizar ciertos actos, buenos o malos, sino que esas acciones son constitutivos intrínsecos de su naturaleza individual: «[...] ¿cuál es el motivo por el que este hombre cometerá con seguridad este pecado? La respuesta es fácil: es que de otro modo no sería este hombre». ${ }^{83}$

El acto libre de la criatura racional es contingente, no porque exista en ella la capacidad real de obrar de otro modo, sino, como lo dice expresamente Leibniz, porque la serie completa de las cosas en la que ésta se halla contenida no es necesaria, sino que fue elegida libremente por Dios. ${ }^{84}$ De esta forma el problema se traslada al plano de la libertad divina, porque entonces pareciera que debe atribuirse a Dios la determinación de la bondad o maldad de los actos de las criaturas elegidas, al elegir la serie actual de cosas. Esta línea de argumentación nos conduciría a la consideración de la estrategia global de Leibniz en su intento de justificación de Dios, lo cual excede los límites del presente trabajo. ${ }^{85}$

Leibniz cree no necesitar ir tan lejos para garantizar la responsabilidad y la imputabilidad en el acto de elección. Para ello solo hace falta considerar la voluntad actualmente determinada hacia el bien o hacia el mal como un ultimum datum en el orden de la imputabilidad moral, desligando esta consideración de todo tipo de indagación etiológica. En rigor, el único requisito indispensable para la justicia del castigo de una acción mala es que ésta proceda de la voluntad del sujeto, independientemente de las circunstancias que la hayan propiciado. ${ }^{86}$

Aun cuando la razón última de la voluntad pueda remitirse a Dios o a la naturaleza de las cosas, la culpa y el castigo corresponden con justicia al pecador, porque $«[. .$.$] en todos los juicios, para infligir una pena, es suficiente juzgar que existe$ una voluntad reconocida como muy mala y deliberada, cualquiera sea su origen. ¿Qué necedad es esta de los críticos de la justicia divina, que para oponerse al castigo quieren ir al infinito, más allá de la voluntad cierta del criminal?». ${ }^{87}$ Las criaturas no son excusables de sus propios pecados, porque más allá de las inclinaciones que proceden de la corrupción de su naturaleza -en virtud del pecado original y demás circunstancias que influyen en la elección mala-, ellas obran con espontaneidad y libertad, vestigios indelebles de la imagen divina en el alma. ${ }^{88}$

\footnotetext{
${ }^{81}$ Grua II, 490.

${ }^{84}$ A VI, 4B, 1592. Eunsa, pp. 61-82.

${ }^{86}$ A VI, 1, 542, § 13.

${ }^{87}$ A VI, 3, 138; A VI, 4B, 1576.

${ }^{88} \mathrm{GP}$ VI, $453, \S 97$.
}

82 GP VI, 107-108, § 9; GP VI, 363, § 414.

${ }^{83}$ A VI, 4B, 1576 (trad. OFC 2, 195); A VI, 4B, 1603.

${ }^{85}$ Para ello véase A. Echavarría, Metafísica leibniziana de la permisión del mal. Pamplona: Eunsa, 2011; A. Echavarría, «Impecabilidad divina: ¿Atributo moral o metafísico? La "necesidad moral" como presupuesto modal para una justificación de Dios», en A. L. González (ed.) (2011), Posibilidad, contingencia, necesidad, existencia. Estudios en los 300 años de la Teodicea de Leibniz. Pamplona: 
Ahora bien, si en el orden de la «imputabilidad» Leibniz considera que no debe irse más allá de la voluntad determinada de la criatura, en el orden de la «causalidad» que conduce a la acción, no tiene ningún reparo en ir más allá de la misma voluntad de la criatura, situándola en la serie de percepciones e inclinaciones que la determinan. Leibniz no puede concebir que la voluntad creada sea el origen absoluto del defecto de su acción, porque «[...] nadie se hace malo voluntariamente, de otro modo ya lo sería antes de llegar a serlo». ${ }^{89} \mathrm{Si}$ la voluntad misma fuese la causa del mal en su acción, habría que buscar a su vez una causa de esta voluntad, y se iría al infinito. Nadie se hace voluntariamente malo, porque nadie es causa voluntaria de su propia voluntad. ${ }^{90}$

Al situar el fundamento último de la autodeterminación en la espontaneidad de la sustancia libre, Leibniz pretende dejar a salvo la participación activa de ella en la conformación del mundo. Eso es lo que permite a su vez dejar intacto el carácter imputable de las acciones. En virtud de su espontaneidad racional, la criatura se convierte en un agente que contribuye, con sus buenas o malas acciones, a constituir una armonía universal de la cual ella misma es a su vez expresión. ${ }^{91}$

En tal sentido, resultan acertadas las palabras de G. Van Riet, quien se refiere a la doctrina de Leibniz sobre la imputabilidad en los siguientes términos: «La distinción entre el bien y el mal no queda por lo tanto suprimida. Es buena la voluntad que sigue la atracción de la razón; es mala aquella que sigue la inclinación sensible sin considerar la ley de la razón. El hombre que tiene una voluntad mala, deliberada, merece la condenación; aquella que quiere el bien obtendrá la felicidad. Pero, ¿puede el hombre evitar el mal? Sí, a condición de que quiera. Pero, ¿puede? Todo parece indicar que, según Leibniz, este poder no es dado a todos, sino que depende de la naturaleza individual de cada uno, de las circunstancias, en resumen, del lugar que cada uno ocupa en el orden universal». ${ }^{92}$

\section{CONCLUSIÓN: VALORACIÓN CRÍTICA DE LA DOCTRINA LEIBNIZIANA DE LA LIBERTAD}

Concluiremos con una reflexión crítica sobre la fundamentación leibniziana de la capacidad de autodeterminación de la voluntad libre. Según se ha visto, Leibniz quiere sostener que la voluntad de las sustancias racionales es libre, pero al mismo tiempo completamente determinada. "Contingentemente» determinada, sin duda, si consideramos las cosas desde un punto de vista lógico, pero realmente determinada hasta su más ínfimo detalle. Según Leibniz, dejar espacio para cualquier indeterminación en la voluntad, por pequeña que fuera, conduciría a un absurdo, porque haría imposible dar razón de los actos de la criatura $-\mathrm{y}$, naturalmente, un acto sin razón no es libre, ni es siquiera acto-. Toda indeterminación implicaría de suyo una imperfección. Ahora bien, con ello Leibniz parece pasar por alto una importante distinción, presente en la filosofía escolástica -a la que tan atento él mismo estaba-, entre lo que podríamos calificar como indeterminación «pasiva» e indeterminación «activa». La indeterminación pasiva es la propia de una potencia que, en virtud de su imperfección, todavía no se ha determinado frente a opciones opuestas; la indeterminación «activa», por el contrario, es la de una potencia activa que, en virtud de

\footnotetext{
${ }^{89}$ A VI, 3, 136 (trad. OFC 2, 51).

${ }^{90}$ A VI, 3, 137-138.

${ }^{91}$ Véase al respecto F. Piro, Spontaneitá e ragion sufficiente, p. 221.

${ }^{92}$ G. Van Riet, «La liberté. Saint Thomas et Leibniz», en Atti del Congresso Internazionale Tommaso d'Aquino nel suo settimo centenario (Roma-Napoli, 17-24 Aprile 1974). Napoli: Edizione Domenicane Italiane, 1977, vol. 5: «L'agire morale», pp. 368-372; p. 370. La traducción es mía.
} 
su misma eminencia o perfección, se encuentra por encima de las opciones que se le presentan, teniendo cierto dominio sobre ellas. ${ }^{93}$

Leibniz sólo es capaz de concebir el primer tipo de indeterminación, y por eso niega esta cualidad a la voluntad creada. Ahora bien, según la concepción clásica de la libertad, con la que Leibniz pretende situarse en continuidad, la indeterminación propia de la voluntad libre, es fundamentalmente una indeterminación «activa» $y$ «dominadora». Paradójicamente, se trata de una indeterminación que encuentra su fundamento en una determinación ontológica fundamental. En efecto, la voluntad creada posee por naturaleza una inclinación y una determinación constitutiva, no hacia este o aquel bien en particular, sino hacia el bien considerado universalmente. ${ }^{94}$ Precisamente porque tiende con una determinación e inclinación absolutas hacia aquello común que comparece en cada una de las instanciaciones concretas del «bien», no tiende con una inclinación absoluta a ninguno de los bienes considerados en particular.

Esta inclinación natural al bien universalmente considerado, es el fundamento de la radical indeterminación que la voluntad creada posee respecto de todo bien particular o finito. ${ }^{95}$ Esto no significa que la voluntad sea «indiferente», en el sentido de que no tenga más inclinación hacia una cosa que hacia otra. La radical inclinación de la voluntad al bien en general es el fundamento de que la voluntad se pueda sentir inclinada o atraída por los diferentes bienes que le presenta la inteligencia -a los cuales quiere siempre sub ratione boni ${ }^{96}$. La determinación natural de la voluntad es una inclinación excedente con respecto a los bienes singulares que se le presentan, y eso es lo que funda su «indeterminación activa».

Aquella apertura «trascendental» de la voluntad al bien, que posibilita la apetición de todo bien particular, hace al mismo tiempo que la voluntad tenga un dominio sobre el juicio que la determina a querer los bienes particulares hic et nunc. Entonces, por más que previamente al acto de elección la voluntad pueda estar inclinada -sea por su naturaleza, sea en virtud de ciertos hábitos adquiridos, sea por la percepción vehemente, sensible o intelectual-, hacia determinados bienes, no obstante ningún bien particular la atraerá con suficiente fuerza como para determinarla de modo infalible.

Que el bien sea presentado al sujeto por la inteligencia es una condición necesaria para que se produzca un acto de elección, porque éste nunca puede producirse sin una «razón» o un «motivo». En tal sentido, la inteligencia es el «alma» de la libertad -como sostiene el mismo Leibniz-, porque contribuye a conformar el acto de elección determinando al último juicio práctico en el orden de la «especificación». Sin embargo, en cuanto al «ejercicio», es la voluntad la que se determina a sí misma libremente, ${ }^{97}$ porque conserva la potestad sobre el último juicio práctico que constituye la elección. ${ }^{98}$ Como dice Millán-Puelles: «[...] se ha de tener en cuenta que, si por un lado es muy cierto que la voluntad queda infaliblemente determinada por el último juicio práctico el que concluye y cierra la deliberación-, por otro lado es igualmente cierto que un juicio práctico no es último porque el entendimiento lo decida (al entendimiento no le pertenece el decidir), sino porque la voluntad le hace ser último, y por ello estriba en el dominio de la voluntad sobre los propios actos calificados de libres». ${ }^{99}$ La potestad de la voluntad de recibir o rechazar la inclinación a los bienes que se le presentan es lo que

\footnotetext{
93 Tomás de Aquino, Summa Contra Gentiles, I, c. 82.

${ }^{94}$ Tomás de Aquino, De veritate, q. 22 a. 6 ad 5.

95 Tomás de Aquino, De veritate, q. 24 a. 7 co.

96 Tomás de Aquino, De veritate, q. 22 a. 6 co.

${ }^{97}$ Tomás de Aquino, Summa Theologiae, I, q. 83 a. 3 co.

98 Tomás de Aquino, Summa Theologiae, I, q. 83 a. 3 ad 2.

${ }^{99}$ A. Millán-Puelles, El valor de la libertad, p. 117.
} 
hace que dichas inclinaciones no sean la «causa» de la elección, sino a lo sumo su «motivo». 100

Es cierto que Leibniz sitúa de modo expreso la raíz de la contingencia de la libertad en la insuficiencia motivadora de los bienes particulares que se le presentan al sujeto racional: «Los tomistas sitúan la libertad en el poder de la voluntad en virtud de la cual ésta se eleva por encima de todo bien finito, de modo que puede oponerle resistencia». ${ }^{101}$ No obstante, está completamente ausente en su planteamiento la dimensión de apertura universal de la voluntad al bien, enraizada en la apertura universal del intelecto al ente como tal -en este sentido, Leibniz no es lo suficientemente «intelectualista». No se da entonces en la criatura racional una auténtica tensión entre la tendencia al bien universal y los bienes concretos que se le presentan, sino que la tendencia al bien no excede nunca los límites que le impone el horizonte de la constelación de percepciones que conforman su naturaleza individual. Al hacer depender el acto de la voluntad de la inclinación prevalente, pareciera no haber en Leibniz una suficiente distinción entre el apetito «natural»-la tendencia que se sigue en la sustancia en virtud de su forma o naturaleza-, y el apetito «elícito» consiguiente al conocimiento intelectual. Así, se da una suerte de reducción del ámbito de la libertad al de la voluntas ut natura, ya que cada naturaleza individual tiende a los bienes particulares que se le presentan con la misma infalibilidad con la que la voluntad tiende al bien universal.

Ahora bien, al no aceptar que la libertad creada tiene un radical dominio actual y no meramente diacrónico sobre el ejercicio del juicio que la determina, Leibniz es incapaz de situar la raíz última de la responsabilidad moral de las acciones en la misma libertad creada. La imputación de las acciones al agente que las realiza no es más que el cumplimiento de un «destino» ya señalado por la constitución ontológica del mismo sujeto, para que se realice a través de él la mayor perfección posible del universo.

Agustín ECHAVARRÍA es Doctor en Filosofía por la Universidad de Navarra, (2010).

Líneas de investigación:

Filosofía moderna, Leibniz, Metafísica y teología natural.

Publicaciones recientes:

(2011) «Leibniz's Conception of God's Permissive Will», en P. Rateau (ed.), Lectures et interprétations des Essais de Théodicée de G. W. Leibniz, Studia Leibnitiana, Sonderheft 40, pp. 191-209.

(2011) Metafísica leibniziana de la permisión del mal. Pamplona: Eunsa, 484 p., ISBN: 978-84313-2793-4.

Dirección electrónica: aechavarria@unav.es

\footnotetext{
${ }^{100}$ Sobre la distinción entre la «causa» y la «razón» o motivo de la acción, véase J. M. Torralba, «La libertad posible. Acerca de la noción leibniziana de «inclinar sin necesidad»», p. 287.

${ }^{101}$ A VI, 4B, 1446 (trad. OFC 2, 129).
} 